\title{
Pengembangan Kapasitas Inovasi Pengelola Pusat Kegiatan Belajar Masyarakat (PKBM) Melalui Pembelajaran Transformatif
}

\author{
Entoh Tohani \\ Program Studi Pendidikan Non-Formal \\ Universitas Negeri Yogyakarta \\ tohani@uny.ac.id
}

Received: 13 August 2021; Revised: 02 October 2021; Accepted: 14 December 2021

DOI: http://dx.doi.org/10.37905/aksara.8.1.425-436.2022

\begin{abstract}
Abstrak
Tulisan ini berusaha memberikan pemahaman mengenai pembelajaran transformative untuk meningkatkan kapasitas inovasi pengelola PKBM dalam rangka mewujudkan lembaga PKBM menjadi lembaga yang professional memberdayakan masyarakat. Pentingnya kapasitas inovasi pengelola dikembangkan sebab perubahan lingkungan yang cepat telah menuntut kemampuan adaptasi lembaga pendidikan. Tulisan ini dilakukan dengan analisis literatur, dan disusun mendasarkan pada kajian substansi literatur baik dalam bentuk buku referensi maupun artikel jurnal yang dipublikasi. Pembelajaran transformative sebagai instrument penting perlu dilakukan dalam rangka membentuk kapasitas inovasi pengelola PKBM dengan memfokuskan pada perubahan pandangan secara kritis kelompok sasaran dan dilakulan dialogis dalam proses pembelajarannya.
\end{abstract}

Kata kunci: Kapasitas, inovasi, pembelajaran, transformative, PKBM

\begin{abstract}
This paper seeks to provide an understanding of transformative learning to increase the innovation capacity of the community learning center managers in order to realize CLC institutions into professional institutions that empower the community. It is important that the innovation capacity of managers is developed because the rapid environmental changes have demanded the adaptability of educational institutions. This paper was carried out by analyzing the literature, and was compiled based on the study of the substance of the literature, both in the form of reference books and published journal articles. Transformative learning as an important instrument needs to be done in order to build the innovation capacity of the CLC managers by focusing on changing the views of the target group critically and doing a dialogue in the learning process.
\end{abstract}

Keywords: Capacity, innovation, teaching, transformative, CLC

\section{PENDAHULUAN}

Pusat Kegiatan Belajar Masyarakat (PKBM) atau Community Learning Center merupakan lembaga pendidikan nonformal yang dapat dikelola baik perseorangan, organisasi, maupun masyarakat memiliki peran strategis dalam mewujudkan warga masyarakat yang berkualitas. Lembaga ini bertujuan menyediakan kesempatan belajar bagi warga masyarakat, menciptakan komunikasi antara masyarakat dan pihak pemerintah, menyediakan literatur informatif bagi masyarakat local, menyediakan program pelatihan, dan menjadikan masyarakat gemar belajar (UNESCO, 2001). Di Indonesi, menurut Kemdikbud (2018) jjumlah PKBM mencapai 8.700 lembaga dengan sebagian besar merupakan PKBM yang dikelola swasta berjumlah 8.609 lembaga (http://referensi.data.kemdikbud.go.id/index31.php). Di Provinsi DIY sendiri jumlah PKBM mencapai 278 lembaga yang mana dari jumlah ini mayoritas belum terakreditasi baik program maupun lembaganya misalnya di Kota Yogyakarta dari 18 PKBM hanya 7 lembaga yang memiliki program pendidikan terakreditasi (Dirjen Bindikmas, 2018). 
Namun demikian, jumlah PKBM yang besar ini menunjukkan suatu potensi untuk memajukan kehidupan masyarakat Indonesia melalui layanan pendidikan yang berbasis masyarakat sendiri khususnya bagi mereka yang belum dapat terlayani oleh lembaga pendidikan formal.

Keberhasilan PKBM dalam mencapai tujuan pendidikan yang ditetapkan sangat tergantung pada kemampuan pengelola sebagai tenaga kependidikan nonformal yang memiliki peran strategis dalam kegiatan mendidik dan memberdayakan masyarakat. Dalam lembaga pendidikan nonformal, pengelola berfungsi sebagai manajer sekaligus pemimpin yang dapat menggerakkan sumber daya yang dimiliki secara efektif dan efesien dan memotivasi individu-individu termasuk warga belajar untuk berpartisipasi aktif dalam proses pendidikan yang dilaksanakan.

Salah satu kemampuan pengelola PKBM yang urgen adalah bagaimana pengelola mampu berinovasi dalam pengembangkan PKBM agar proses memberdayakan masyarakat menjadi lebih efektif, efesien, dan bermakna. Artinya, mereka harus memiliki kapasitas inovasi (innovation capacity) yang dapat dimaknai sebagai kemampuan untuk menghasilkan inovasi atau melakukan penemuan dalam meningkatkan produktivitas dan kebermanfaatan lembaga pendidikan... as the ability to continuously transform knowledge and ideas into new products, processes and systems for the benefit of the firm and its stakeholders (Lawson \& Samson, 2001). Kepemilikan kapasitas ini akan menjamin lembaga pendidikan ini tetap berkembang dan mampu memenangkan persaingan dalam rangka memperoleh sumber daya yang ada di masyarakat. Kapasitas inovasi merupakan modal lembaga pendidikan yang dapat digunakan untuk memenangkan persaingan (Drucker, 1993) terutama dalam lingkungan yang terus berubah seperti saat ini terjadi revolusi industry 4.0 yang menimbulkan perubahan skala besar dalam kehidupan.

Namun disayangkan, kapasitas inovasi pengelola PKBM belum optimal. Hal ini ditunjukkan dengan temuan beberapa kajian mengenai PKBM yang membuktikan bahwa kemampuan berinovasi masih rendah ditandari dengan terdapat perilaku pengelola yang cenderung kuat berorientasi vertical dalam pelaksanaan kegiatan pendidikan (Tohani, 2013), aktivitas fundrising masih belum optimal dilakukan oleh pengelolan (Rizka \& Hardiansyah, 2017), program pendidikan kurang beragam, kekurangan pendanaan, pengelola sibuk dengan kegiatan lainnya (Raharjo, Suminar \& Mu arifudin, 2015), tutor kurang memiliki kemampuan merencanakan pembelajaran dengan baik (Septiani, 2015), kekurangan gedung pembelajaran (Darlan, 2017), menghadapi kendala birokrasi yang menghambat kinerja lembaga (Agung, 2007), dan kapasitas pengembangan dan capaian mutu program maupun kelembagaan PKBM belum optimal (Tohani, 2010b; Tohani 2009; Tohani, 2013). Kapasitas inovasi pengelola menjadi dasar bagi PKBM untuk selalu meningkatkan kinerjanya. Oleh karena itu, perlu dilakukan upaya mengembangkan kapasitas ini yang salah satunya adalah dengan menyelenggarakan pembelajaran yang berbasis pada pemaknaan pandangan/pengalaman pengelola sebagai titik tolak pemberdayaan, yaitu dengan pembelajaran transformative (transformative learning).

Proses pembelajaran transformative pada dasarnya merupakan proses internal dalam diri individu untuk memaknai pengalaman-pengalaman yang dimiliki untuk selanjutnya memperoleh pengetahuan baru yang dapat digunakan untuk mengatasi masalah hidup dan kehidupannya (Mezirow, 2003). Pembelajaran transformative 
merupakan instrument untuk mengasilkan berbagai gagasan atau ide inovatif yang dapat berguna dalam memenangkan sumber daya dalam lingkungan yang cepat berubah. Pentingnya pembelajaran ini dilakukan dalam rangka mengembangkan kapasitas inovasi pengelola PKBM dikarenakan pada aspek pengembangan kualitas sumber daya manusia PKBM kenyataan bahwa proses pengembangan kapasitas pengelola dominan dilakukan oleh pihak eksternal misalnya pemerintah/instansi pendidikan baik ditingkat local, regional maupun nasional dengan menyelenggarakan berbagai pendidikan dan pelatihan yang kurang berkelanjutan dan kurang memperhatikan pengalaman pengelola PKBM sebagai subyek aktif pemberdayaan (Tohani, 2013).

Terkait dengan hal di atas, dalam konteks mengoptimalkan fungsi PKBM dalam memberdayakan masyarakat, proses pembelajaran 427ransformative perlu direncanakan dan dikembangkan secara bermakna untuk mengembangkan kemampuan inovasi pengelola PKBM agar mereka lebih mampu berkinerja dengan optimal sehingga dapat memiliki kemampuan bersaing dalam lingkungan pendidikan yang selalu dan terus berubah.

\section{METODE PENELITIAN}

Penelitian ini dilakukan dengan pendekatan analisis isi literatur. Pengumpulan data dilakukan dengan cara memiliki referensi baik buku referensi, hasil penelitian, maupun artikel jurnal terakreditasi yang membahas mengenai kondisi dan perkembangan PKBM yang ada di masyarakat dalam konteks pemberdayaan masyarakat, pembelajaran transformative learning dalan rangka mengembangkan warga belajar, dan pemberdayaan masyarakat. Substansi pada literatur selanjutnya dianalisis dengan cara mengambil tema/topik relevan, menghubungkan tema/topik, dan mengkonstruksinya sesuai tujuan penelitian. Dialog dengan teman sejawat dalam bentuk diskusi dan meminta pendapat dilakukan untuk memperkuat jelas tema atau topik kajian yang mengarah pada perumusan hasil penelitian yang diharapkan.

\section{HASIL DAN PEMBAHASAN}

\section{Pusat Kegiatan Belajar Masyarakat (PKBM)}

Pusat Kegiatan Belajar Masyarakat atau community learning centre (CLC) diartikan oleh sebagai suatu tempat belajar local (setempat) di luar system pendidikan formal, baik berada di perdesaan maupun di tempat-tempat lain, biasanya dibangun dan dikelola oleh masyarakat setempat supaya untuk menyediakan berbagai kesempatan belajar bagi pembangunan masyarakat dan peningkatan kualitas hidup (UNESCO, 2006; 2011) untuk keuntungan warga belajar, keluarga dan masyarakat (Smith, 2005). Pada dasarnya, lembaga pendidikan ini merupakan institusi yang didirikan oleh, dari, dan untuk masyarakat, atau merupakan perwujudan lembaga pendidikan yang didasarkan pada prinsip community based education (Jalal \& Supriadi, 2000). Meskipun pada awalnya berdirinya banyak PKBM yang bergantung pada bantuan dan dana dari pemerintah, dalam jangka panjang diharapkan pada sebagian besar PKBM akan tumbuh kemandiriannya.

UNESCO (2003) menjelaskan keberadaan PKBM di tengah-tengah masyarakat baik yang diinisiatifi oleh pemerintah, lembaga swasta masyarakat (LSM) atau pun masyarakat sendiri diharapkan dalam perkembangannya menjadi pusat (center) pembelajaran bagi setiap warga masyarakat (www.unesco.org). Sebagai pusat, 
dimungkinkan setiap warga masyarakat tanpa terkecuali dapat menjangkau untuk memanfaatkannya guna meningkatkan kualitas dirinya baik pengetahuan, sikap, dan perilakunya melalui proses pembelajaran yang dilakukan di PKBM. Kamil (2006) menjelaskan adanya PKBM pada dasarnya ditujukan untuk terbentuknya perilaku warga masyarakat untuk aktif belajar selama hidupnya secara terus-menerus agar dapat menjadi mandiri (self-reliant), meningkatkan kualitas hidupnya, serta memberikan kontribusi pada pengembangan masyarakatnya.

Terkait dengan pandangan bahwa PKBM sebagai pusat belajar, maka dapat dikemukakan bahwa tujuan pendirian PKBM adalah untuk menjadikan warga masyarakat menjadi sukses dalam beragam konteks (Smith, 2005:14). Hal ini mengandung makna bahwa adanya kesempatan yang disediakan oleh PKBM berupa kesempatan belajar yang terus-menerus dalam memecahkan berbagai permasalahan yang dihadapi, sehingga mereka melalui proses belajar mampu memahami masalah, mencari solusi pemecahan masalah dan selanjutnya bertindak untuk mengatasi masalah yang dihadapi tersebut, dan menjadikan warga masyarakat yang baik, pekerja yang bertanggung jawab, pembelajaran mandiri, dan menjadi individu kreatif dan inovatif (Jennings, 2005). Dalam jangka panjang, melalui PKBM terciptakan individu-individu yang gemar belajar yang mempengaruhi dan menjadikan lingkungan masyarakatnya menjadi sebuah masyarakat gemar yang belajar (learning society).

Sebagai sumber belajar, PKBM dapat menyelenggarakan berbagai program pendidikan dan/atau pemberdayaan masyarakat seperti pendidikan yang diarahkan pada pengembangan diri dan pemanfaatan waktu luang dan hobby, pendidikan untuk peningkatan kemampuan berusaha seperti pendidikan kewirausahaan dan pelatihan dan pendidikan kerja, pendidikan untuk mengembangkan lingkungan seperti pendidikan lingkungan dan pendidikan kebencanaan, pendidikan untuk meningkatkan kualitas kehidupan keagamaan, dsb.

\section{Kapasitas Inovasi Pengelola PKBM}

PKBM memiliki kemampuan yang dapat menghasilkan berbagai kegiatan pendidikan dan pengelolaan lembaga yang mengarah pada ketercapaian tujuan pendidikan. PKBM perlu dikelola dengan efektif dan akuntabel dalam aspek sumber daya, program, kemitraan, dsb (UNESCO, 2003). PKBM perlu mengarahkan pada pencapaian kinerja yang menekankan pada pencapaian prestasi yang efektif, terjadinya berbagai perbaikan-perbaikan, dan terwujud jaminan mutu (Bush \& Coleman, 2006) baik pada aspek penyelenggaraan program pendidikan maupun pengelolaan PKBM.

Kapasitas inovasi menjadi faktor kunci untuk keberhasilan PKBM. Kapasitas inovasi dimaknai sebagai kemampuan individu atau lembaga dalam menghasilkan produk/layanan, proses, pemasaran, dan sebagainya yang lebih bermakna/kebaruan (novelty) dan membawa manfaat. Momeni, Neilsen, \& Kafash (2015) mengungkapkan bahwa kapasitas inovasi dibutuhkan oleh organisasi sebagai suatu keunggulan kompetitif dalam perkembangan lingkungan. Menurut mereka, kapasitas ini adalah kemampuan menciptakan layanan atau produk baru, teknologi baru, praktik administratif yang baru, dan sebagai suatu intelegensi dan kreativitas, kemampuan menciptakan belajar yang efektif, dan menciptakan pengetahuan baru (Suryono \& Tohani, 2016). 
Inovasi sendiri dimaknai sebagai sesuatu yang baru yang dapat berupa ide, praktik atau obyek yang dipandang baru oleh individu atau kelompok masyarakat, terlepas apakah ide, praktik atau obyek tersebut secara obyektif baru (Rogers, 1983). Dalam dunia bisnis, Zawilak, et al (2012) menyatakan kapasitas inovasi suatu organisasi dapat dibedakan menjadi empat yaitu: a) kapasitas pengembangan teknologi, b) kapasitas operasi (pekerjaan), dan d) kapasitas transaksi. Sedangkan Fullan (2007) menyatakan dalam dunia pendidikan inovasi dapat dilakukan dalam bentuk tiga aspek yaitu: kurikulum atau materi ajar, pendekatan pembelajaran, dan asumsi-asumsi pedagogic. Bentuk inovasi tersebut dapat diperoleh dengan melakukan perubahan baik secara radikal (radical innovation) maupaun secara bertahap (incremental innovation) (Nahapiet \& Ghosal, 1998).

Kapasitas inovasi pengelola PKBM harus dibangun secara terarah dengan cara menelaah dan mengembang komponen penting organisasi. Lawson \& Samson (2001) menjelaskan kapasitas inovasi terbentuk apabila dalam lingkungan organisasi terwujud visi dan strategi yang jelas, memiliki kompetensi inti, mengelola ide dan kreativitas, struktur dan sistem organisasi yang mendukung, penciptaan budaya dan iklim dan pengelolaan teknologi yang tepat.

Gambar 1. Model kapasitas inovasi

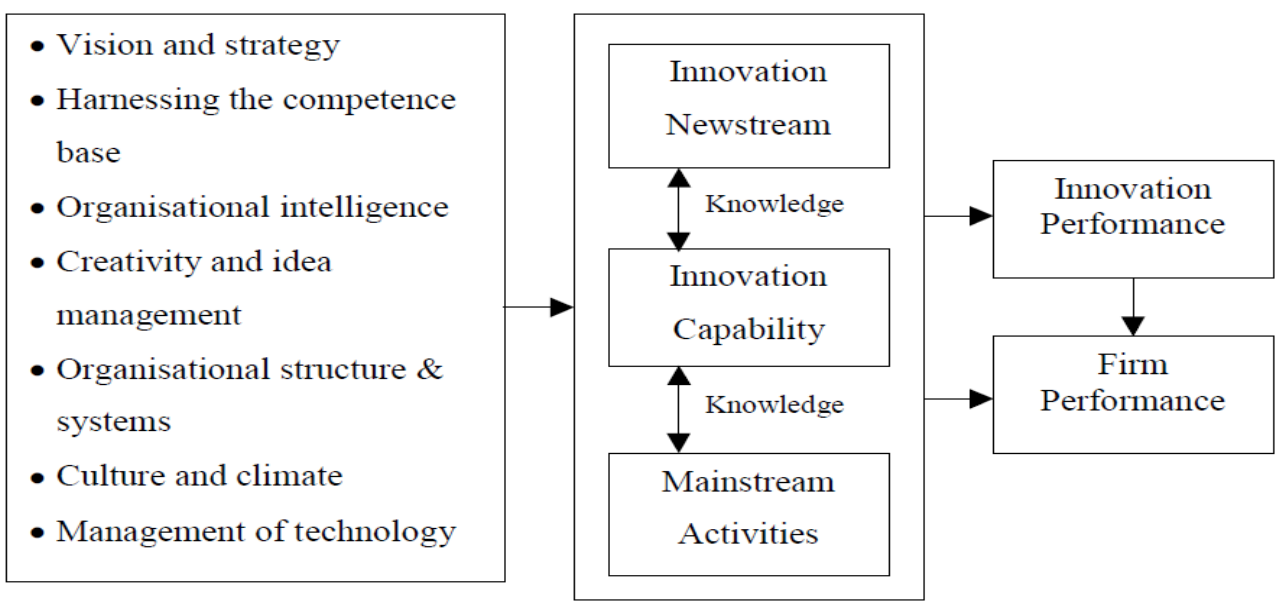

\section{Pembelajaran Transformatif}

Kemampuan berinovasi pengelola PKBM terbentuk tidak dengan sendirinya, namun perlu dibentuk melalui proses belajar transformatif (transformatif learning) yang bertumpu pada kemandirian individu. Pembelajaran transformatif dimaknai sebagai belajar yang mentransformasi adalah pembelajaran yang mengubah kerangka acuan yang bermasalah-serangkaian asumsi dan harapan yang tetap (kebiasaan pikiran, perspektif makna, pola pikir) untuk menjadikannya lebih inklusif, terbuka, reflektif, dan mampu berubah secara emosional. Kerangka referensi seperti itu lebih baik daripada yang lain karena mereka lebih cenderung menghasilkan kepercayaan dan pendapat yang akan terbukti lebih benar atau dibenarkan untuk memandu tindakan (Mezirow, 1997). Melalui pembelajaran ini, diharapkan pengelola PKBM dapat merubah pemahaman, pandangan, kebiasaaan, cara berfikir, dan perasaan yang kurang tepat menjadi sesuatu yang baru (Mezirow, 2003). Menurutnya Mezirow (2000) proses pembelajaran transformatif terjadi dalam 10 langkah sebagai berikut: 
1. Dilema yang membingungkan

2. Pemeriksaan diri dengan perasaan bersalah atau malu

3. Penilaian kritis terhadap asumsi

4. Pengakuan bahwa ketidakpuasan dan proses transformasi seseorang dibagikan dan bahwa orang lain telah menegosiasikan perubahan serupa

5. Eksplorasi opsi untuk peran, hubungan, dan tindakan baru

6. Perencanaan suatu tindakan

7. Akuisisi pengetahuan dan keterampilan untuk mengimplementasikan rencana seseorang

8. Secara sementara mencoba peran baru

9. Membangun kompetensi dan kepercayaan diri dalam peran dan hubungan baru

10. Reintegrasi ke dalam kehidupan seseorang berdasarkan kondisi yang ditentukan oleh perspektif baru seseorang.

Pembelajaran transformatif memiliki karakteristik kunci yaitu: terjadinya proses perubahan baik adaptif maupun transformatif, interpretasi pengalaman dan pengetahuan, menggunakan skema referensi, pemaknaan dan perspektif, emansipasi, rekfleksi kristis terhadap asumsi-asumsi pandangan terhadap dunia, pengembangan kesadaran dan perubahan melalui dialog, adanya kebutuhan dan penyebab yang dibutuhkan, pemobilisasian makna/kata-kata, dan pendidik sebagai katalisator (Jackson, 2008; Liu, 2020).

Pembelajaran transformatif diharapkan menghasilkan perubahan sebagai suatu bentuk pergerakan pendidikan (Gardner, 2008). Perubahan perilaku pengelola PKBM sebagai kelompok sasaran pembelajaran ini dapat berbentuk sebagaimana Hoggan (2016) kemukakan tipologi outcome meliputi: pandangan dunia (worldview) seperti perubahan asumsi, kepercayaan, sikap dan harapan, cara-cara menginterpretasi pengalaman, pandangan lebih kompleks/komprehensif, dan pemahaman baru; perubahan diri (self) meliputi pemberdayaan/tanggung jawab, indentitas, pengetahuan diri sendiri, perubahan personalitas, dan personal narratives; epistemology mencakup lebih dapat membedakan, lebih terbuka, dan penggunaan cara mengetahuan yang esktra rasional; ontology mencakup elajar ini mencakup: pengalaman kehidupan yang efektif, cara mengada (being), dan sikap/moral; perilaku mencakup konsistensi tindakan dengan pandangan baru, tindakan social, praktik professional, dan keterampilan; dan kapasitas mencakup meningkatan kognitif, kesadaran dan spiritualitas.

Agar terjadi perubahan perilaku kelompok sasaran, strategi pembelajaran perlu dirancang secara optimal. Kasworm \& Bowles (2012) menjelaskan strategi yang dapat dilakukan untuk menciptakan belajar transformatif adalah:

a) Mengembangkan refleksi diri, kemampuan emosional untuk terbuka, dan disjuncture kritis. Intervensi ini meliputi pengembangan yang disengaja refleksi diri melalui log reflektif, esai, blog, atau kegiatan pengalaman seperti bermain peran yang fokus pada disorientasi dilema, terlibat dalam pengalaman budaya yang membawa perhatian pada masalah ras, jenis kelamin, kelas, kekuasaan, dan hak istimewa;

b) Strategi untuk refleksi kritis. Proyek penelitian tindakan, proyek penulisan kolaboratif, keterlibatan dalam kritik, atau penggunaan penilaian kritis untuk 
membantu pelajar memeriksa asumsi mereka, pengalaman masa lalu, dan pandangan dunia;

c) Penciptaan lingkungan sosial yang mendukung. Menciptakan lingkungan belajar yang aman, dapat dipercaya, dan saling menghormati untuk mendukung peserta didik dalam transformasi mengingat bahwa refleksi kritis dan dialog dapat menimbulkan rasa kerentanan.

d) Penggunaan seni, sastra, film, dan drama sebagai alat untuk pembelajaran transformatif untuk mengekspos peserta didik ke berbagai konteks, realitas, dan perspektif.

e) Proses holistik, afektif, dan spiritual. Desain disengaja yang memfokuskan atau merangkul aspek non-kognitif dari pembelajaran transformatif seperti emosi, perhatian, dan spiritualitas (Enkhtur \& Yamamoto, 2017).

Mendasarkan pada kajian teori di atas, dapat rumuskan kerangka pengembangan model pengembangan kapasitas inovasi pengelola PKBM melalui pembelajaran transformatif dalam rangka pemberdayaan masyarakat sebagai berikut:

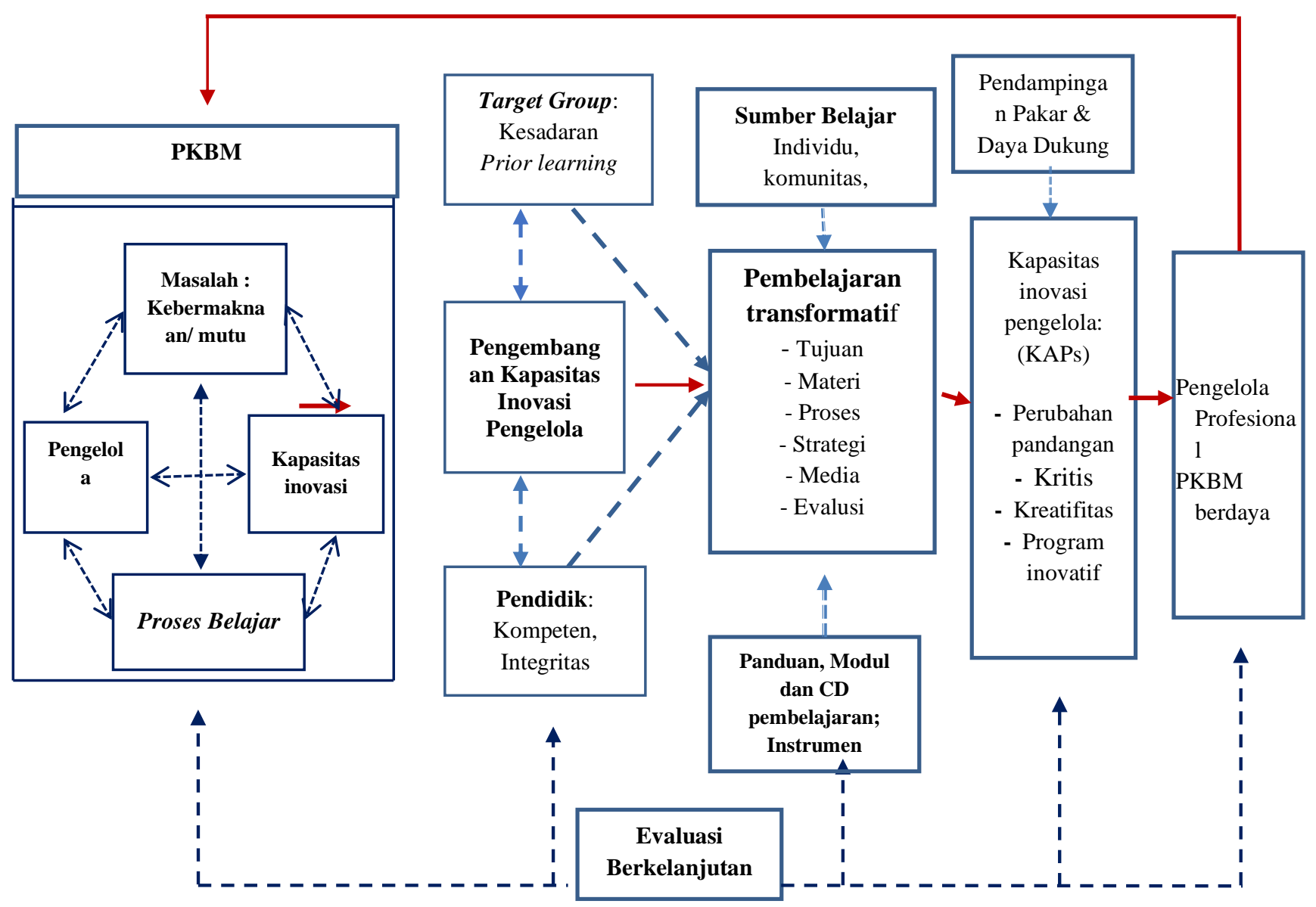

Bagan 2. Desain pembelajaran

Mendasarkan began ini, pembelajaran transformative perlu dilakukan dengan: 
- Memahami masalah riil terkait dengan kapasitas peningatan inovasi yang ada di PKBM dan memahami bagaimana proses belajar yang dilakukan oleh para pengelola dan apa hasil yang diperolehnya. Pemahaman masalah riil seharusnya melibatkan kelompok sasaran dan dilakukan dengan refleksi bersama.

- Terkait dengan masalah riil, tujuan pembelajaran harus dinyatakan secara jelas, disepakati dan dipahami secara bersama oleh pihak yang berkepentingan agar semua merasa memiliki andil dan berkeinginan untuk mewujudkannya. Tujuan utama pembelajaran transformative ini adalah untuk mengembangkan kemampuan berinovasi pengelola sehingga mereka dapat menjadi personalia yang professional dan menjadikan PKBM berdaya.

- Pembelajaran harus dilakukan secara dialogis dan melibatkan kesadaran kritis kelompok sasaran pembelajaran guna menjamin pembelajaran terjadi karena dorongan dan moivasi objektif dari kelompok sasaran. Koordinasi, sosialisasi, dan komunikasi yang bersifat penyadaran dan pendidikan kepada kelompok sasaran dapat dilakukan sebelum pembelajaran dilakukan.

- Pendidik yang terlibat harus merupakan individu-individu yang memiliki kompentensi sesuai tujuan pembelajaran dan memiliki integritas luhur yang menjamin terwujud personifikasi kompeten dan humanis dalam pembelajaran.

- Substansi pembelajaran dikembangkan dengan mendasarkan pada pengalaman kelompok sasaran, berbasis pengetahuan yang sudah dimiliki kelompok saran, berbasis realitas yang terjadi dan menarik untuk dipelajari serta memotivasi kelompok sasaran untuk mempelajarinya. Substansi pembelajaran dapat dikemas dengan menggunakan bantuan media pembelajaran yang menarik dan efektif.

- Proses pembelajaran harus dilakukan dengan pendekatan dialogis, dilakukan secara terbuka, dan dalam suasana kebersamaan.

- Proses pembelajaran dapat mengunakan sumber belajar baik individu, organisasi atau masyarakat yang tersedia di masyarakat dan dapat diakses secara optimal oleh kelompok sasaran.

- Penilaian baik terhadap pembelajaran maupun pengelolaan pembelajaran dilakukan secara berkelanjutan dengan menekankan pada perubahan perilaku objektif kelompok sasaran, pengembangan pandangan dan kemampuan kritisinovatif kelompok sasaran.

- Penguatan hasil pembelajaran perlu dilakukan dengan memberikan fasilitas dan pemotivasian kepada kelompok sasaran setelah kegiatan pembelajaran dilakukan.

Dalam pelaksanaan pembelajaran transformative ini, pengembang harus menyadari kendala yang dapat terjadi pada implementasinya sehingga mempengaruhi pencapaian tujuan pendidikan. Kendala utama yang dapat muncul antara lain ketidakmampuan kelompok sasaran yang tidak dapat memahami atau tidak melakukan berfikir kritis terhadap praktik yang dilakukannya (Nairn, 2012). Kendala lain adalah perbedaan latar belakang pengembang atau pendidik dengan kelompok sasaran, persepsi yang keliru dari kelompok sasaran terhadap pelaksanaan pembelajaran yang mana pendidikan bukan menjadi kebutuhan kelompok sasaran, hubungan edukasi yang terbina kurang harmonis, dan lingkungan sosialbudaya yang kurang mengapresiasi perbedaan dalam pembelajaran. 
AKSARA: Jurnal Ilmu Pendidikan Nonformal

P-ISSN 2407-8018 E-ISSN 2721-7310 DOI prefix 10.37905

Volume 08, (1), January 2022

http://ejurnal.pps.ung.ac.id/index.php/Aksara

\section{KESIMPULAN}

Pengembangan kapasitas inovasi pengelola PKBM menjadi keharusan dalam rangka membentuk kapasitas personalia lembaga PKBM agar menjadi individu-individu yang professional dan mampu menjadikan lembaga berbasis masyarakat ini menjadi lembaga yang berfungsi besar dalam membentuk masyarakat yang memiliki terdidik dan berdaya. Dalam perubahan lingkungan yang cepat, kapasitas berinovasi menjadi instrument penting lembaga ini untuk menyesuaikan diri dengan tuntutan dan persaingan yang dapat muncul. Pembelajaran transformative menjadi upaya urgen yang dapat dilakukan untuk mengembangkan kapasitas invoasi dalam bentuk melakukan tindakan pendidikan yang didasarkan pada perubahan pandangan kelompok sasaran mengenai realitas atau permasalahan yang terjadi dalam pengelolaan lembaga ini. Pembelajaran ini akan efektif dan efesien bila komitmen bersama dan kesamaan pandangan terjadi diantara kelompok sasaran dan kelompok sasaran dengan pendidik atau pengembang.

\section{DAFTAR PUSTAKA}

Agung, Iskandar. (2007). Hambatan birokratis dalam penyelenggaraan Pusat Kegiatan Belajar Masyarakat. Jurnal Pendidikan dan Kebudayaan, nomor 068, tahun ke13, September 2007, 909-922.

Bush, T., \& Coleman, M. (2006). Kepemimpinan pendidikan. Terjemahan Farrurozi. Yogyakarta: IRCISoD

Darlan, Muhammad Norsanie. (2017). Management of community Learning Activities Center (CLAC) in District Kotawaringin Timur. Journal of Nonformal Education, 3 (2) (2017) 125-131.

Dirjen Bindikmas. (2018). Data SKB dan PKBM per 2018. Diakses dari http://bindikmas.kemdikbud.go.id/program-dan-layanan/data-lembaga pada tanggal 6 Maret 2019.

Drucker, P. F. (1993). innovation and entrepreneurship: Practice and principles. California: Perfect Bound.

Enkhtur, Ariunaa \& Tamamoto, Berverley Anne. (2017). Transformatif Learning Theory and its Application in Higher Education Settings: A Review Paper. Diakses dari www.ir.library.osaka-u.ac.jp/dsape. Diakses 13 Maret 2019.

Fullan, M. (2007). The meaning of educational change. Columbia: Teachers College Press.

Gardner, M. \& Kelly, Ursula, A. (2008). Narrating transformative learning in education. New York: Palgrave Macmillan ${ }^{\text {TM }}$

Hoggan, Chad D. (2016). Transformative Learning as a Metatheory: Definition, Criteria, and Typology. Adult Education Quarterly 66(1), Vol. 66(1) 57-75.

Irmawati, Ais. (2017). Peran Pusat Kegiatan Belajar Masyarakat (PKBM) dalam mengurangi buta aksara di Kabupaten Karimun. Jurnal Pendidikan dan Kebudayaan, Vol. 2, Nomor 1, Juni 2017, hal. 81-96.

Jackson, M.G. (2008). Transformative Learning for a New Worldview: Learning to Think Differently. New York: PALGRAVE MACMILLAN

Jalal, Fasli \& Supriadi, Dedi.(2001). Reformasi pendidikan dalam konteks otonomi daerah. Yogyakarta: Adicita Karya Nusa. 
Jennings, Wayne. (2005). Community learning centers. Diakses dari www.eric.ed.gov, tanggal 13 Maret 2019.

Lawson, Benn \& Samson, Danny. (2001). Developing Innovation Capability In Organisations: A Dynamic Capabilities Approach. International Journal of Innovation Management, Vol. 5, No. 3 (September 2001) Pp. 377-400

Liu, K. (2020). Critical Reflection for Transformative Learning: Understanding ePortfolios in Teacher Education. Las Vegas: Springer

Mezirow, J. (1997). Transformatif Learning: Theory to Practice', New Directions for Adult and Continuing Education, 74, 5-12.

Mezirow, J. (2000). Learning to think like an adult: Core concepts of transformation theory. In J. Mezirow \& Associates (Eds.), Learning as transformation: Critical perspectives on a theory in progress (pp. 3-33). San Francisco, CA: Jossey-Bass.

Mezirow, J. (2003). Transformative learning as discourse. Journal of Transformative Education, 1(1), Januari 2003, 58-63.

Martharini, TR., Rasyad A., \& Moedzakir. D. (2016). Pengembangan Buku Panduan Pembelajaran Transformatif Untuk Program Pendampingan Anak Jalanan. Journal of Nonformal Education and Community Empowerment 5 (1), 2016, 1-8.

Nairn, S., Chambers, D., Thompson, S., McGarry, J., \& Chambers, K. (2012). Reflexivity and habitus: opportunities and constraints on transformative learning. Nursing Philosophy, 13(3), 189-201. doi:10.1111/j.1466769x.2011.00530.x

Nahapiet, J., \& Ghosal, N. (1998). Social Capital, Intelectual Capital. The Organizational Advantage. Academy of Management Review, 23(2), 243-266.

Nusantara, \& Moedzakir. (2016). Pembelajaran transformatif pada kegiatan pendampingan anak jalanan di Kota Malang. Jurnal Pendidikan dan Pembelajaran (JPP) 22 (1), 2016, 039-051.

Raharjo, Tri Joko., Suminar, Tri \& Mu'arifuddin. (2016). Peran Pusat Kegiatan Belajar Masyarakat dalam menanggulangi kemiskinan melalui pendidikan nonformal di jawa tengah. Journal of Nonformal Education, 2 (1) (2016); Https://Doi.Org/10.15294/Jne.V2i1.5310

Rizak, Arief Muhammad \& Hardiansyah, Nila. 2017. Analisis strategi fund raising dalam penyelenggaraan program pendidikan nonformal pada Pusat Kegiatan Belajar Masyarakat Ceria. Journal of Nonformal Education, 3 (2) (2017).

Rogers, E. (1983). Diffusion of Innovations. New York: The Free Press.

Rumiyati \& Sundiman, Didi. (2017). Peran manajemen pengetahuan pada kapasitas inovasi Usaha Kecil dan Menengah (UKM): (Studi pada UKM di kota Sampit). E-Jurnal Profit (Jurnal Penerapan Ilmu Manajemen dan Kewirausahaan), Vol. 2/No. 2/2017/136-148.

Septiani, Mita. (2015). Pengalaman Pusat Kegiatan Belajar Masyarakat (PKBM) dalam memfasilitasi masyarakat belajar sepanjang hayat. Jurnal Ilmiah VISI PPTK PAUDNI, Vol. 10, No.2, Desember 2015, 67-76

Smith, William J. (2005). The community learning centre, from values to result: Key issues and challenges for building and sustaining school-community collaboration. Quebec: LEARN

Sugito, \& Tohani, Entoh. (2018). Kebutuhan, inovasi dan modal sosial pengrajin batik di Bantul. Laporan Penelitian tidak diterbitkan, LPPM UNY Yogyakarta. 
Suryono, Yoyon \& Tohani, Entoh. (2016). Inovasi pendidikan nonformal. Yogyakarta: Graha Cendikia

Tohani, Entoh. (2009). Evaluasi pelaksnaaan program PKBM dalam konteks pemberdayaan masyarakat di Daerah Istimewa Yogyakarta. Jurnal Penelitian Ilmu Pendidikan, vol 2, No. 2, September 2009, 198-205.

Tohani, Entoh. (2010a). Pemetaan tingkat mutu pendidikan Pada Pusat Kegiatan Belajar Masyarakat (PKBM) Di Daerah Istimewa Yogyakarta. Diklus, Volume 14, Nomor 1, Maret 2010, Hal. 15-27.

Tohani, Entoh.(2010b). Strategi pengembangan kapasitas PKBM sebagai penyedia jasa layanan pendidikan. Jurnal Penelitian Ilmu Pendidikan, vol 3, No. 2, September 2010, 178-190.

Tohani, Entoh. (2013). Evaluasi kelembagaan Pusat Kegiatan Belajar Masyarakat (PKBM) sebagai agent pengembangan masyarakat di DIY. Jurnal VISI PTKPPNF, Vol. 5, No. 2 Desember 2010, Kemendikbud.

Kamil, Mustopa. (2006). Pendidkan nonformal: Pengembangan melalui Pusat Kegiatan Masyarakat (PKBM) di Indonesia (sebuah pembelajaran dari Kominkan Jepang). Bandung: Alfabeta.

UNESCO. (2011). Sustainability of community learning centres: Community ownership and support. Bangkok: UNESCO Bangkok

UNESCO. (2006). Community Empowerment through Community Learning Centers in Mid and Far Western Regions of Nepal. Katmandhu: UNESCO Kathmandu

UNESCO. (2003). CLC management handbook. Diakses dari www.unesco.org. diakses pada tanggal 12 Agustus 2008.

UNESCO. (2004). Multi purposes community learning center. Diakses dari http://portal.unesco.org, tanggal 7 November 2016.

Zawislak, P.A, Alves, A.C, Tellogamara, J., Baribeux, D., \& Reichert, F.M (2012). Innovation capacity: from technology development to transaction capability. Journal of Technology Management and Innovation, Vol. 7, no. 2 Juli 2012.

Yusnita, Maya \& Wahyudin, Nanang. (2017). Entrepreneurial Leadership melalui kapasitas inovasi sebagai upaya peningkatan keunggulan kompetitif UMKM di Era Masyarakat Ekonomi ASEAN (MEA): Kajian Usaha Mikro di Kabupaten Bangka). Integrated Journal of Business and Economics (IJBE) Vol.1 No.1 2017, 10-18. 
AKSARA: Jurnal Ilmu Pendidikan Nonformal

P-ISSN 2407-8018 E-ISSN 2721-7310 DOI prefix 10.37905

Volume 08 , (1), January 2022

http://ejurnal.pps.ung.ac.id/index.php/Aksara 